\title{
Partial diazoxide responsiveness in a neonate with hyperinsulinism due to homozygous ABCC8 mutation
} \author{
John Barton5, M Dattani1,3 and Pratik Shah1,3 \\ 1Department of Paediatric Endocrinology, Great Ormond Street Hospital for Children, London, UK, 2Department of \\ Endocrinology, Royal Hospital for Sick Children, Edinburgh, UK, ${ }^{3}$ Genetics and Genomic Medicine Programme, Great \\ Institute of Child Health, University College London, London, UK, ${ }^{4}$ Institute of Biomedical and Clinical Science, \\ University of Exeter Medical School, Exeter, UK, and 5Department of Paediatric Endocrinology, Bristol Royal Hospital \\ for Children, Bristol, UK
}

Sarah Kiff1,2, Carolyn Babb1, Maria Guemes1,3, Antonia Dastamani1, Clare Gilbert1, Sarah E Flanagan4, Sian Ellard4,
Correspondence should be addressed to P Shah

Email

pratik.shah@gosh.nhs.uk

\section{Summary}

We report a case of partial diazoxide responsiveness in a child with severe congenital hyperinsulinaemic hypoglycaemia $(\mathrm{CHI})$ due to a homozygous $A B C C 8$ mutation. A term baby, with birth weight $3.8 \mathrm{~kg}$, born to consanguineous parents presented on day 1 of life with hypoglycaemia. Hypoglycaemia screen confirmed CHI. Diazoxide was commenced on day 7 due to ongoing elevated glucose requirements ( $15 \mathrm{mg} / \mathrm{kg} / \mathrm{min})$, but despite escalation to a maximum dose $(15 \mathrm{mg} / \mathrm{kg} /$ day), intravenous (i.v.) glucose requirement remained high (13 $\mathrm{mg} / \mathrm{kg} / \mathrm{min})$. Genetic testing demonstrated a homozygous $A B C C 8$ splicing mutation (c.2041-1G>C), consistent with a diffuse form of $\mathrm{CHI}$. Diazoxide treatment was therefore stopped and subcutaneous (s.c.) octreotide infusion commenced. Despite this, s.c. glucagon and i.v. glucose were required to prevent hypoglycaemia. A trial of sirolimus and near-total pancreatectomy were considered, however due to the significant morbidity potentially associated with these, a further trial of diazoxide was commenced at 1.5 months of age. At a dose of $10 \mathrm{mg} / \mathrm{kg} /$ day of diazoxide and $40 \mu \mathrm{g} / \mathrm{kg} /$ day of octreotide, both i.v. glucose and s.c. glucagon were stopped as normoglycaemia was achieved. $\mathrm{CHI}$ due to homozygous $A B C C 8$ mutation poses management difficulties if the somatostatin analogue octreotide is insufficient to prevent hypoglycaemia. Diazoxide unresponsiveness is often thought to be a hallmark of recessively inherited $A B C C 8$ mutations. This patient was initially thought to be non-responsive, but this case highlights that a further trial of diazoxide is warranted, where other available treatments are associated with significant risk of morbidity.

\section{Learning points:}

- Homozygous $A B C C 8$ mutations are commonly thought to cause diazoxide non-responsive hyperinsulinaemic hypoglycaemia.

- This case highlights that partial diazoxide responsiveness in homozygous $A B C C 8$ mutations may be present.

- Trial of diazoxide treatment in combination with octreotide is warranted prior to considering alternative treatments, such as sirolimus or near-total pancreatectomy, which are associated with more significant side effects. 


\section{Background}

Congenital hyperinsulinaemic hypoglycaemia (CHI) is the most common cause of persistent severe hypoglycaemia presenting in the neonatal period (1). The underlying cause of hyperinsulinism and the presence of diffuse or focal disease can be determined by genetic, radiological and histopathological investigations (2). Response to medical treatment can sometimes be predicted by genotype, particularly in those affected by diffuse disease caused by a homozygous mutation in the ABCC 8 or KCNJ11 genes. These genes encode components of the voltage gated potassium channel of pancreatic beta cells (SUR1 and Kir6.2 respectively). Mutation results in unregulated release of insulin from the beta cells and subsequent hypoglycaemia (3).

Diazoxide acts directly via the SUR 1 subunit of the voltage gated potassium channel, reducing depolarisation and therefore preventing unregulated insulin release. When homozygous ABCC8 mutations are present, diazoxide is unable to act to prevent hypoglycaemia (4).

The clinical case of a neonate with $\mathrm{CHI}$ due to homozygous ABCC8 mutations is presented. In this case, initial non-response to diazoxide was seen, but a further trial in combination with octreotide appeared to be successful, suggesting a partial response. This was unexpected in the case of a patient with homozygous ABCC8 mutations, and allowed avoidance of alternative medical and surgical management of $\mathrm{CHI}$ which is associated with significant morbidity.

\section{Case presentation}

A term male infant (birth weight $3.8 \mathrm{~kg},+0.52$ SDS) was the first baby born to consanguineous parents, with a maternal history of gestational diabetes. He presented with hypoglycaemia on day 1 of life. A hypoglycaemia screen confirmed CHI (Table 1).
Diazoxide was commenced on day 7 due to ongoing elevated intravenous (i.v.) glucose requirements $(15 \mathrm{mg} / \mathrm{kg} / \mathrm{min})$. Despite gradual escalation in diazoxide dose to $15 \mathrm{mg} / \mathrm{kg} /$ day, there was minimal response in glucose requirement $(13 \mathrm{mg} / \mathrm{kg} / \mathrm{min})$. On day 25 he was transferred to a centre specialising in $\mathrm{CHI}$ management.

\section{Investigation}

On admission to the specialist centre, on day 25 of life, point-of-care test blood glucose was carried out hourly. Hypoglycaemia was defined as blood glucose (BG) $<3.5 \mathrm{mmol} / \mathrm{L}$. A centrally inserted venous catheter was placed to allow blood investigations and delivery of concentrated intravenous glucose.

Diazoxide treatment was discontinued due to the previously reported poor response, and to allow a controlled hypoglycaemia screen to be carried out. This confirmed CHI (Table 1).

Genetic testing demonstrated a homozygous $A B C C 8$ splicing mutation (c.2041-1G>C), consistent with diffuse form of CHI. Poor response to diazoxide was therefore anticipated. Both parents were shown to be heterozygous carriers of the mutation.

\section{Treatment}

Given the anticipated and previously reported poor response to diazoxide, a $10 \mu \mathrm{g} / \mathrm{kg} /$ day subcutaneous (s.c.) octreotide infusion was commenced on day 32. Diazoxide was subsequently restarted in addition on day 39 , and was gradually increased to a maximum dose of $15 \mathrm{mg} / \mathrm{kg} / \mathrm{day}$ by day 44 . Furosemide and spironolactone were given to prevent fluid overload.

Ongoing hypoglycaemia was seen on hourly blood glucose profile and therefore octreotide was increased to a maximum dose of $30 \mu \mathrm{g} / \mathrm{kg} /$ day over a period of a further 16 days. At $30 \mu \mathrm{g} / \mathrm{kg} /$ day octreotide and $15 \mathrm{mg} / \mathrm{kg} / \mathrm{day}$

Table 1 Day 3 and day 31 hypoglycaemia screens: showing inappropriately elevated insulin concentration in the context of hypoglycaemia, without mobilisation of non-esterified fatty acids and beta-hydroxybutyrate production. Consistent with diagnosis of hyperinsulinaemic hypoglycaemia.

\begin{tabular}{l}
\hline Biochemistry \\
\hline Glucose $(\mathrm{mmol} / \mathrm{L})$ \\
Insulin $(\mathrm{mU} / \mathrm{L})$ \\
Non-esterified fatty acid $(\mathrm{mmol} / \mathrm{L})$ \\
Beta-hydroxybutyrate $(\mathrm{mmol} / \mathrm{L})$ \\
Lactate $(\mathrm{mmol} / \mathrm{L})$ \\
Ammonia $(\mu \mathrm{mol} / \mathrm{L})$ \\
Cortisol $(\mathrm{nmol} / \mathrm{L})$ \\
\hline
\end{tabular}

\begin{tabular}{c}
\hline Day 3: results \\
\hline 2 \\
21 \\
0.24 \\
$<0.05$ \\
1.1 \\
$<50$ \\
263 \\
\hline
\end{tabular}

\begin{tabular}{cll}
\hline Day 31: results & & Reference range \\
\cline { 1 - 1 } 2.1 & & $2.6-5.5$ \\
8.8 & $<5$ when hypoglycaemic \\
0.24 & $<2$ \\
$<0.05$ & $<50$ \\
18 & \\
364 & \\
\hline
\end{tabular}


diazoxide treatment, i.v. glucose requirement reduced to $1.7 \mathrm{mg} / \mathrm{kg} / \mathrm{min}$, i.v. glucagon reduced to $1 \mu \mathrm{g} / \mathrm{kg} / \mathrm{h}$ and the baby received high-energy milk equivalent to $8.4 \mathrm{mg} /$ $\mathrm{kg} / \mathrm{min}$ of carbohydrate as a continuous nasogastric (NG) feed. Given that poor response to diazoxide had been anticipated and no clear response attributable to diazoxide alone had been seen during this second trial of diazoxide, the drug was discontinued again and the octreotide dose further increased to $40 \mu \mathrm{g} / \mathrm{kg} /$ day.

During this period episodes of hypoglycaemia recurred on hourly glucose profile, requiring an increase in i.v. glucose delivery (from 1.7 to $3.5 \mathrm{mg} / \mathrm{kg} / \mathrm{min}$ ) and s.c. glucagon (from 1 to $5 \mu \mathrm{g} / \mathrm{kg} / \mathrm{h}$ ).

Further management options were considered, including use of sirolimus (mTOR inhibitor) or neartotal pancreatectomy. Neither of these options were thought to be without significant risk of morbidity. The baby had postnatally acquired CMV infection. Use of sirolimus in a neonate in this scenario has not previously been documented, and would require close monitoring of the viral load and potential treatment with anti-viral medication. The possible complications of near-total pancreatectomy include ongoing $\mathrm{CHI}$, diabetes mellitus, pancreatic exocrine insufficiency and damage to the common bile duct.

To avoid both of these treatments, a further trial of diazoxide with furosemide and spironolactone was commenced on day 66. On this occasion, at a dose of $10 \mathrm{mg} / \mathrm{kg} /$ day of diazoxide, both i.v. glucose and s.c. glucagon were stopped as normoglycaemia was achieved (Fig. 1).

From day 72, octreotide was given by 6 hourly s.c. injection at $40 \mu \mathrm{g} / \mathrm{kg} / \mathrm{day}$. Milk feeds via gastrostomy provided the equivalent of $11.9 \mathrm{mg} / \mathrm{kg} / \mathrm{min}$ of carbohydrate.

\section{Outcome and follow-up}

The baby was discharged at 3.5 months of age treated with $10 \mathrm{mg} / \mathrm{kg} /$ day of oral diazoxide and $40 \mu \mathrm{g} / \mathrm{kg} / \mathrm{day}$ of octreotide given by 6 hourly s.c. injection. A feeding regimen consisting of a standard infant formula supplemented with additional carbohydrate of $12 \%$ concentration was well tolerated. Three hourly bolus feeds were given during the daytime and an overnight continuous feed to total $150 \mathrm{~mL} / \mathrm{kg} /$ day. Blood glucose was stable on this regimen and fasting ability on 6-h controlled fast was demonstrated.

Regular reassessment was carried out. At the age of 13 months, the child remained treated with octreotide $(38 \mu \mathrm{g} / \mathrm{kg} /$ day $)$ and diazoxide $(9.5 \mathrm{mg} / \mathrm{kg} /$ day) and on 3 hourly daytime feeds (solids and cow's milk) and a continuous overnight feed via gastrostomy. A controlled fast demonstrated hypoglycaemia at $4 \mathrm{~h}$, indicating ongoing severe $\mathrm{CHI}$.

At the age of 23 months, the child was treated with octreotide $(38 \mu \mathrm{g} / \mathrm{kg} / \mathrm{day})$ and diazoxide $(9.5 \mathrm{mg} / \mathrm{kg} / \mathrm{day})$ on 3-hourly daytime feeds (solids and cow's milk) and a

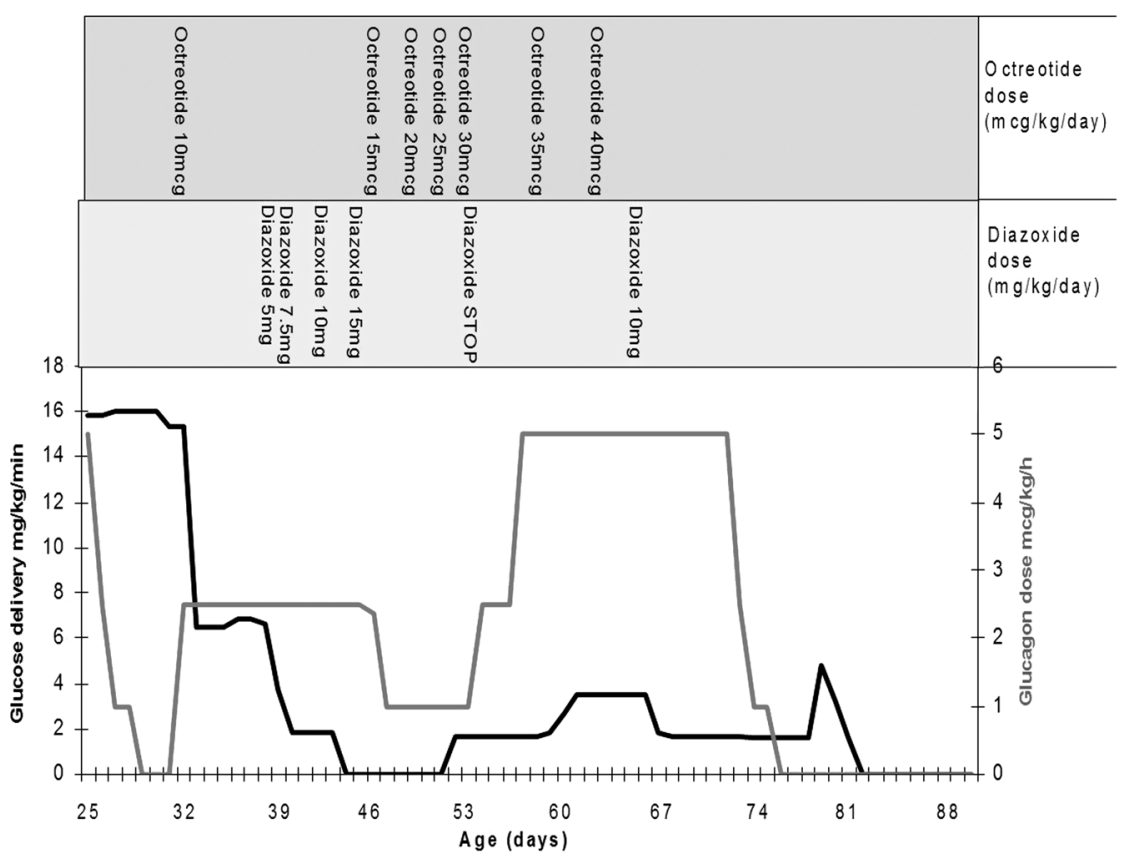

\section{Figure 1}

I.v. glucose delivery $(\mathrm{mg} / \mathrm{kg} / \mathrm{min})$ and subcutaneous glucagon dose $(\mu \mathrm{g} / \mathrm{kg} / \mathrm{h})$ on each day of age during $\mathrm{CHI}$ Centre admission. Diazoxide treatment had been commenced in the local hospital but was discontinued on admission to allow a controlled hypoglycaemia screen to be carried out. 
Table 2 Clinical, biochemical and therapeutic responses of the patient at most recent assessment.

\begin{tabular}{|c|c|}
\hline \multicolumn{2}{|c|}{ Latest clinical and biochemical assessment } \\
\hline Age & 25 months \\
\hline Current weight & $11.15 \mathrm{~kg}(-1.3 \mathrm{SDS})$ \\
\hline Current height & $79.8 \mathrm{~cm}(-1.9 \mathrm{SDS})$ \\
\hline Current height velocity & $7.19 \mathrm{~cm} /$ year (-1.5 SDS) \\
\hline \multirow[t]{4}{*}{ Current medications } & Lanreotide 30 mg (4 weekly/s.c.) \\
\hline & Diazoxide 8 mg/kg/day (TDS/oral) \\
\hline & $\begin{array}{l}\text { Spironolactone } 1.6 \mathrm{mg} / \mathrm{kg} / \mathrm{day} \\
\text { (BD/oral) }\end{array}$ \\
\hline & Furosemide 1.6 mg/kg/day (BD/oral) \\
\hline \multirow[t]{3}{*}{ Current feeding plan } & Daytime: fed every $4 \mathrm{~h}$ with 3 meals \\
\hline & $\begin{array}{l}\text { (solids) and snacks and } 100-200 \mathrm{~mL} \\
\text { cow's milk with added vitajoule (total } \\
10 \% \text { carbohydrate) }\end{array}$ \\
\hline & $\begin{array}{l}\text { Overnight: Nutrini } 35 \mathrm{~mL} / \mathrm{h} \text { for } 11 \mathrm{~h} \\
\text { via gastrostomy }\end{array}$ \\
\hline
\end{tabular}

continuous overnight feed via gastrostomy. No episodes of hypoglycaemia occurred on hourly blood glucose profile over $24 \mathrm{~h}$. Hypoglycaemia again developed after $4 \mathrm{~h}$ of controlled fast.

Lanreotide (a long acting somatostatin analogue) was commenced at 23 months of age at a dose of $30 \mathrm{mg}$ by deep s.c. injection every 4 weeks. Octreotide was subsequently weaned and stopped by 25.5 months of age. The transition from lanreotide to octreotide was not made at an earlier stage due to barriers to hospital attendance for adequate monitoring of the transition. Further assessment at 25.5 months of age showed adequate growth (Table 2). A plan for repeat assessment with blood glucose profile and controlled fast is planned. If stability in glycaemic control is demonstrated, the diazoxide dose will be weaned with careful monitoring of response.

\section{Discussion}

CHI patients with recessive inactivating mutations in ABCC8 or KCNJ11 genes have defective production, turnover or trafficking of $\mathrm{K}_{\mathrm{ATP}}$ channels resulting in constant depolarisation of the beta cell membrane and therefore persistent insulin secretion $(5,6)$. The mechanism of action of diazoxide is via the SUR1 subunit of the $\mathrm{K}_{\text {ATP }}$ channel, reducing depolarisation. In patients with a homozygous recessive ABCC 8 gene mutation, diazoxide therefore does not usually prevent insulin secretion.

Diazoxide unresponsiveness is often thought to be a hallmark of recessively inherited ABCC8 mutations. A large review of 417 cases of $\mathrm{CHI}$ carried out at The Children's Hospital of Philadelphia found that no patient with a homozygous $A B C C 8$ mutation was responsive to diazoxide (7). Dekel et al. (8) report a patient carrying a biallelic mutation in the ABCC 8 gene that had diazoxide responsive $\mathrm{CHI}$. This child had a compound heterozygosity for two mutations in the ABCC8 gene, (c.3992-9G->A) and (p.Phe1388del). The authors postulated that although one of these mutations is known to cause severe non-diazoxide responsive disease (with in vitro studies demonstrating no channel activity by the mutant protein), the compound heterozygous nature in this case may have resulted in a milder phenotype as the maternally inherited allele has been associated with $\mathrm{CHI}$ of variable severity.

Arya et al. (9) also reported a case of a child with a compound heterozygous mutation in the ABCC8 gene who was responsive to diazoxide. A missense mutation in p.Arg526Cys and a frameshift mutation c.1879delC (p.His627fs*20) was identified. Response to diazoxide was also confirmed in this case in functional studies of the mutant $\mathrm{K}_{\mathrm{ATP}}$ channel in a hamster model.

Diazoxide responsiveness in a child with a homozygous $A B C C 8$ gene mutation has not been reported in the literature prior to this case. We describe a patient with $\mathrm{CHI}$ due to a homozygous $A B C C 8$ splicing mutation (c.2041-1G>C) who did appear to show partial response to diazoxide, sufficient to avoid additional treatment with subtotal pancreatectomy or an mTOR inhibitor.

Marked clinical heterogeneity has previously been reported in siblings with identical mutations in ABCC8 gene (10). Although the mechanism for this variability is unknown, postulated explanations include effect of modifying genes, and epigenetic and environmental factors. Differences in the splicing factor machinery may influence the phenotypic expression of the splice site mutation, resulting in individuals expressing variable proportions of the functioning transcript.

Our patient has a canonical splice site which is likely to result in aberrant splicing and nonsense mediated decay of the formed protein. In this case, the splice site is not predicted to be abolished, but reduced in strength. The occurrence of some normal splicing would result in some $\mathrm{K}_{\text {ATP }}$ channels which do reach the cell surface. These would be normal in structure and function and therefore able to respond to diazoxide. This may explain a partial response to diazoxide in this case.

It could be argued that $\mathrm{CHI}$ cases tend to become milder overtime and therefore a reduction in severity of disease is responsible for the apparent response to diazoxide in this patient. A number of individual cases of spontaneous resolution have been reported (11). A review of 21 patients consecutively presenting with $\mathrm{CHI}$ due to 
$\mathrm{K}_{\text {ATP }}$ channel gene mutations was carried out at one $\mathrm{CHI}$ centre (12). The authors report frequent resolution in CHI that was not predicted by the gene mutation. Complete resolution was seen in some patients with recessively inherited $\mathrm{CHI}$ with homozygous and compound heterozygous mutations. Reduction in severity of $\mathrm{CHI}$, as indicated by reduced diazoxide dose and discontinuation of somatostatin receptor agonists, was seen in all patients. Regular reassessment of disease severity is therefore required to identify disease resolution and avoid the need for escalation of treatment.

In our reported case, it is not possible to accurately identify the relative contribution of octreotide, diazoxide and the natural course of reducing severity of disease on this baby's blood glucose stabilisation. However, the patient had evidence of ongoing severe $\mathrm{CHI}$ at the last clinical reassessment at 23 months of age, with significantly shortened fasting time than would be expected for their age. Therefore resolution of $\mathrm{CHI}$ has not occurred, but similarly full responsiveness to medical treatment has not been seen.

The patient's trial with diazoxide in early life was deemed to be unsuccessful, with only a minor fall in i.v. glucose infusion rate. It is possible that the maximum response was only apparent in combination with octreotide treatment, when glucose infusion rates had already been reduced, or when there may have already been some reduction in disease severity beyond the first month of life.

At present it is not felt appropriate to discontinue trial of diazoxide again, given the very short fasting time of the child. However this will be considered in future if fasting time improves. It is important to minimise treatment burden for patients and their families.

\section{Conclusion}

This case demonstrates that partial diazoxide responsiveness, in combination with octreotide treatment, may be seen in children with homozygous $A B C C 8$ gene mutations. It is essential to assess response to diazoxide carefully, even in patients in whom non-response would be predicted, as this has the potential to avoid the use of treatments with more significant complications and side effects.

\section{Declaration of interest}

The authors declare that there is no conflict of interest that could be perceived as prejudicing the impartiality of the research reported.

\section{Funding}

This research did not receive any specific grant from any funding agency in the public, commercial or not-for-profit sector.

\section{Patient consent}

Written consent has been obtained from the patient's guardian.

\section{Author contribution statement}

Sarah Kiff wrote the first draft. Carolyn Babb, Maria Guemes, Antonia Dastamani and Clare Gilbert reviewed the manuscript. Sarah E Flanagan and Sian Ellard made all the study-specific investigations. John Barton, M Dattani and Pratik Shah were named physicians. Pratik Shah approved the final manuscript and was the corresponding author.

\section{References}

1 Aynsley-Green A, Hussain K, Hall J, Saudubray JM, Nihoul-Fékété C, De Lonlay-Debeney P, Brunelle F, Otonkoski T, Thornton P \& Lindley KJ. Practical management of hyperinsulinism in infancy. Archives of Disease in Childhood: Fetal and Neonatal Edition 200082 F98-F107. (https://doi.org/10.1136/fn.82.2.F98)

2 Senniappan S, Shanti B, James C \& Hussain K. Hyperinsulinaemic hypoglycaemia: genetic mechanisms, diagnosis and management. Journal of Inherited Metabolic Disease 201235 589-601. (https://doi. org/10.1007/s10545-011-9441-2)

3 Pinney SE, MacMullen C, Becker S, Lin YW, Hanna C, Thornton P, Ganguly A, Shyng SL \& Stanley CA. Clinical characteristics and biochemical mechanisms of congenital hyperinsulinism associated with dominant KATP channel mutations. Journal of Clinical Investigation 2008118 2877-2886. (https://doi.org/10.1172/JCI35414)

4 Rozenkova K, Guemes M, Shah P \& Hussain K. The diagnosis and management of hyperinsulinaemic hypoglycaemia. Journal of Clinical Research in Pediatric Endocrinology 20157 86-97. (https://doi. org/10.4274/jcrpe.1891)

5 Azizun Nessa Qadeer H, Aziz Alison M \& Thomas Stephen C. Harmer Andrew Tinker Khalid Hussain molecular mechanisms of congenital hyperinsulinism due to autosomal dominant mutations in ABCC8. Human Molecular Genetics 201524 5142-5153. (https:// doi.org/10.1093/hmg/ddv233)

6 Yan FF, Lin YW, MacMullen C, Ganguly A, Stanley CA \& Shyng SL. Congenital hyperinsulinism-associated $\mathrm{ABCC} 8$ mutations that cause defective trafficking of ATP-sensitive $\mathrm{K}+$ channels: identification and rescue. Diabetes 200756 2339-2348. (https://doi.org/10.2337/db070150)

7 Snider KE, Becker S, Boyajian L, Shyng S-L, MacMullen C, Hughes N, Ganapathy K, Bhatti T, Stanley CA \& Ganguly A. Genotype and phenotype correlations in 417 children with congenital hyperinsulinism. Journal of Clinical Endocrinology and Metabolism 201398 E355-E363. (https://doi.org/10.1210/jc.2012-2169)

8 Dekel B, Lubin D, Modan-Moses D, Quint J, Glaser B \& Meyerovitch J. Compound heterozygosity for the common sulfonylurea receptor mutations can cause mild diazoxide-sensitive hyperinsulinism. Clinical Pediatrics 200241 183-186. (https://doi. org/10.1177/000992280204100310)

9 Arya VB, Aziz Q, Nessa A, Tinker A \& Hussain K. Congenital hyperinsulinism: clinical and molecular characterisation of compound heterozygous ABCC8 mutation responsive to diazoxide therapy. International Journal of Pediatric Endocrinology 201420142. (https://doi.org/10.1186/1687-9856-2014-24)

10 Kapoor RR, Flanagan, SE, Ellard S \& Hussain K. Congenital hyperinsulinism: marked clinical heterogeneity in siblings with 
identical mutations in the ABCC8 gene. Clinical Endocrinology 2012 76 312-313. (https://doi.org/10.1111/j.1365-2265.2011.04203.x)

11 Kumaran A, Kapoor RR, Flanagan SE, Ellard S \& Hussain K.

Congenital hyperinsulinism due to a compound heterozygous ABCC8 mutation with spontaneous resolution at eight weeks. Paediatrics 201073 287-292. (https://doi.org/10.1159/000284394)
12 Salomon-Estebanez M, Flanagan SE, Ellard S, Rigby L, Bowden L, Mohamed Z, Nicholson J, Skae M, Hall C, Craigie R, et al. Conservatively treated congenital hyperinsulinism (CHI) due to K-ATP channel gene mutations: reducing severity over time. Orphanet Journal of Rare Diseases 201611 163. (https://doi.org/10.1186/ s13023-016-0547-3)

Received in final form 20 December 2018

Accepted 8 January 2019 